\title{
USO DA TECNOLOGIA DA INFORMAÇÃO E COMUNICAÇÃO EM UMA SEQUÊNCIA DIDÁTICA INCLUINDO SOFTWARE GEOGEBRA NO ENSINO DA ESTATÍSTICA DESCRITIVA
}

\author{
Use of information and communication technology in a teaching sequence \\ including geogebra software in the teaching of descriptive
}

\author{
Ricardo Fernando de Souza \\ Universidade Cruzeiro do Sul - UNICSUL, prof.ricardofernando@gmail.com \\ Laura Marisa C. Calejon
}

Universidade Cruzeiro do Sul, lauracalejon@gmail.com

\begin{abstract}
Resumo
Este artigo é um recorte de uma pesquisa de mestrado profissionalizante no ensino de ciências e matemática, tratando-se do uso do software GeoGebra no ensinoaprendizagem da estatística descritiva. Surgiu devido à inquietação do pesquisador em relação a suas experiências como professor de matemática na educação básica. Teve como objetivo, analisar a eficiência da sequência didática que inclua o software GeoGebra no ensino da estatística descritiva para alunos do terceiro ano do ensino médio. A metodologia da pesquisa se deu num primeiro momento, em uma revisão da literatura de diferentes autores de referência na área da tecnologia da informação e comunicação TIC's aplicada a educação matemática e da teoria da aprendizagem significativa, bem como, no estudo de caso. Yin (2005, p. 32, apud GIL, 2008, p. 77), aponta que o estudo de caso é um conhecimento empírico, ocorrendo por meios investigativos e contemporâneos em um contexto real, onde o fenômeno a ser estudado e tal contexto, não estão definidos de forma clara. Os resultados coletados por meio de avaliações 1 e 2, apontam a sequência didática incluindo o GeoGebra, eficientes, o que possibilitou na maioria dos alunos o entendimento dos conceitos envolvendo a estatística descritiva.
\end{abstract}

Palavras-chave: TIC’S; Estatística Descritiva; Geogebra.

\section{Abstract}

This article is a cross-section of a professional master's degree research in the teaching of science and mathematics, dealing with the use of GeoGebra software in teaching-learning descriptive statistics. It arose because of the researcher's uneasiness about his experiences as a teacher of mathematics in basic education. The objective of this study was to analyze the efficiency of the didactic sequence that includes GeoGebra software in the teaching of descriptive statistics for third year students of high school. The methodology of the research was given at first, in a review of the literature of different authors of reference in the area of information technology and communication - TIC'S applied to mathematics education and the theory of meaningful learning, as well as in the case study . Yin (2005, p. 32, apud GIL, 2008, p.77), points out that the case study is an empirical knowledge, occurring by investigative and contemporary means in a real context, where the phenomenon to be studied and such context, are not clearly. The results collected through assessments 1 and 2, point to the didactic sequence including 
GeoGebra, efficient, which made it possible for most students to understand the concepts involving descriptive statistics.

Keyword: TIC’S; Descriptive Statistics; GeoGebra.

\section{Introdução}

A organização da educação matemática como área de conhecimento e preocupação dos educadores resulta das dificuldades de aprendizagem dos conteúdos desta disciplina nas diferentes etapas da escolarização e pela aversão que estes conteúdos produzem nos estudantes. D Ambrosio (2006) defende que a identificação da Educação Matemática como uma área prioritária da Educação ocorre na transição do século XIX para o século XX, destacando Dewey (1859-1952) como um dos primeiros pensadores a mencionar explicitamente a educação Matemática e citando o livro Psicologia do Número (1895) de Dewey como uma reação ao formalismo, propondo uma relação cooperativa entre aluno e professor, assim como uma integração entre as diferentes disciplinas. Mais de um século depois os professores e pesquisadores seguem procurando caminhos que permitam fazer do ensino dos conteúdos da matemática uma tarefa agradável e produtiva para professore e alunos. O autor citado atribui a Felix Klein (1849-1925) a defesa de argumentos para organizar o ensino dos conteúdos da matemática baseado em bases psicológicas, levando em consideração o processo psíquico do aluno, de modo a despertar seu interesse pelo conteúdo estudado. A consolidação da educação Matemática como subárea da Matemática e da Educação, tendo uma natureza interdisciplinar ganha maior força no século XX. O exercício da interdisciplinaridade ainda constitui-se como um desafio para encontrar caminhos que de fato oportunizem sua materialização.

A inquietação dos professores que ensinam matemática face ao desempenho dos estudantes constitui-se em um motor poderoso para pesquisar novas formas de ensinar. A estas inquietações somam-se as possibilidades e desafios trazidos pelo progresso da tecnologia da informação e da comunicação. Esta é a proposição deste artigo que faz um recorte de uma pesquisa, em andamento, realizada no Programa de Mestrado no Ensino de Ciências e Matemática oferecido pela Universidade Cruzeiro do Sul. O progresso das TIC se oferece, por um lado, novas possibilidades de organizar contextos de ensino, muitas vezes, por outro lado desafiam e confundem professores e alunos. A pesquisa em andamento objetiva avaliar a efetividade de uma sequência didática que conta com a presença de um software (Geogebra) para ensinar conteúdos de estatística descritiva no Ensino Médio. Constitui-se como objetivo deste artigo analisar a contribuição das TIC na organização de contextos de ensino, refletir sobre o ensino da estatística na educação básica, descrevendo a sequência didática que está em fase de avaliação, assim como resultados parciais encontrados.

\section{Tecnologia da informação e comunicação - TIC}

Inúmeras questões são levantadas em torno do uso das tecnologias de informação e comunicação no âmbito escolar. Essas indagações tem despertado grande interesse na investigação do verdadeiro papel que esta nova era digital exerce ou poderá exercer no desenvolvimento das atividades curriculares, no sentido de promover valores ou não para o desenvolvimento das práticas educativas. 
As tecnologias de informação e comunicação - TIC's trazem novas formas de expressão, abrindo novos horizontes proporcionando interação e possibilitando incorporar a esses fatores, a própria educação, a qual se tornou objeto de investigação para o ensino de conteúdos por meio das especificidades das disciplinas. Assim, podemos pensar na construção do conhecimento na educação, por meio do uso do computador e na atualidade, as TIC e os ambientes virtuais de aprendizagens, dando suporte para a autoria dos sujeitos no processo de cognição.

Ferri, Shimiguel e Calejon (2013) corroboram sobre a importância das tecnologias e comunicação da informação no âmbito educacional. Atualmente, existe uma grande variedade de softwares desenvolvidos para as praticas educativas, inserindo o ensino em uma nova dimensão que se dá por meio dos computadores, proporcionando a este novo ambiente de aprendizagem uma reorganização do pensamento coletivo.

Leivas e Gobbi (2014) acrescentam que as TIC levam desafios aos professores em várias vertentes, por exemplo, a afirmação por parte de alguns professores não terem conhecimentos mais afundo sobre essa ferramenta, como recurso a ser utilizado na proposta pedagógica por meio dos computadores, de outra parte, falta aceitar as mudanças e superarem barreiras para transpor um ensino e propondo problemas com novos desafios, os quais não se conseguem resolver sem o uso da ferramenta tecnológica.

Por outro lado, Leivas e Gobbi, apontam os cuidados que devemos ter ao assumir os recursos tecnológicos, pois estes mesmo que ainda possam ser recursos poderosos e que estão totalmente disseminados em todas as áreas, especialmente na educação, ainda não são capazes de resolver todos os problemas existentes nos planos educacionais, justamente por não garantir por si só, mudanças na prática educativa. Sancho e Hernández (2006, p. 18,) apud Leivas e Gobbi (2014) asseguram ainda que os recursos tecnológicos embora já se consolidaram, tal transformação que revolucionou o mundo, para o mesmo fenômeno, vale para os solos educacionais.

Nessa mesma linha de pensamentos e levando em conta que as TIC vêm substituindo as praticas educativas consideradas ultrapassadas, ainda assim, o uso dessa ferramenta requer habilidades a fim de se atingir o objetivo proposto, portanto, o conteúdo programado e a proposta didática, devem ser diferenciados em relação às práticas adotadas em salas de aula, o que implica em um repensar crítico sendo avaliada e reavaliada regularmente. Nesta perspectiva de criticidade vale a pena sinalizar a reflexão de Bauman (2000) apud Barreto (2009) sobre a problemática relação entre sociedade de produtores e sociedade de consumidores. Uma das decorrências desta relação que segundo Barreto (2009) merece nossa atenção é o estabelecimento de uma sociedade nova e civilizada e outra sociedade considerada velha. Assim, em uma proposta de desvalorização do passado é preciso amar o novo, assumindo-o como referencial, um novo que cabe na lógica do mercado, prontamente assimilado e substituído com a rapidez que produz seu envelhecimento e tornar-se obsoleto. Felinto (2005) apud Barreto (2009) destaca uma dimensão singular das novas tecnologias que se revela na seguinte relação quanto mais misteriosa a configuração da máquina, mais poderosa ela parece ser. 
Com o desenvolvimento tecnológico, basicamente o que muda em relação aos anos que se passaram, está na modalidade de uma comunicação e processamento da informação de forma global com maior velocidade e em diferentes formatos.

Schimiguel et al (2018) aponta que esse processo onde a informação encontra-se disseminada de forma rápida e ao mesmo tempo acessível, deixam os alunos imediatistas, demonstram ser impacientes para um sistema de ensino-aprendizagem, em que na maioria das vezes, impede a capacidade de desenvolvimento de um pensamento reflexível.

Entender que as TIC's, ainda que possa estabelecer relações elencados acima entre professor e aluno, este como sujeito de uma educação contemporânea, vale ressaltar os novos desafios enfrentados conforme recomendação indicada pelos autores Schimiguel et al, 2018: "Os recursos criados pelo progresso da tecnologia da informação e da comunicação criam, por um lado, novas possibilidades de organização de contextos educativos mais atraentes e, por outra parte, trazem uma quantidade de desafios a serem enfrentados pelos professores".

Com o avanço cada vez mais acelerado da tecnologia, os professores precisam estar prontos para atender uma demanda de alunos em que o acesso a informação se da cada vez mais rápido e dinâmico e que acreditam que as TIC's podem ser a solução de todos os problemas educacionais, tornando-os dispersos na maioria das vezes em sala de aula, deixam outras relações interpessoais e acabam isolados o que demonstra que nem sempre a tecnologia ajuda, pelo contrário, pode até prejudicar seu progresso acadêmico dependendo da forma como é utilizada.

Para uma educação eficiente e eficaz, não basta saber apenas os tipos de tecnologias empregadas e sim, a disposição das pessoas em saber utilizar as Tecnologias da Informação e Comunicação para garantir o desenvolvimento entre a educação e a comunicação integralmente. (SCHIMIGUEL et al, 2018). Observa-se, portanto, que o progresso das TIC e a criação de novos recursos não representam uma solução fácil ou mágica para os inúmeros desafios da educação que busca produzir um sujeito crítico, capaz de compreender o mundo em que ele vive e de sentir-se também responsável pela direção que a sociedade pode assumir.

\section{A matemática e o ensino da estatística na educação básica.}

Não é de hoje que o ensino da matemática é tema de grande preocupação e que vem sendo discutido com a finalidade de encontrar soluções na tentativa de superar uma educação tradicional. Nesta lógica, a didática da matemática consistia somente na transmissão dos conteúdos por memorização, pondo de lado habilidades fundamentais dos alunos impedindo o seu desenvolvimento crítico e o pensamento lógico, que podem ser alcançados nesta disciplina, por exemplo, por meio de resoluções de problemas, possibilitando uma auto avaliação de seus resultados. Na grande maioria das vezes, os conteúdos deixam de ser interessantes e úteis, estando desvinculado de seu cotidiano, causando um desinteresse grande pela maioria dos alunos. Tais situações criam problemas constantes como: falta de interesse, reprova aversão à matemática, sendo considerada uma das piores disciplinas da educação básica, senão a pior. 
Fragoso (2011) reforça que a matemática cada vez mais assumi o papel de uma disciplina difícil de estudar, fato que pode ser observado pelas manifestações na grande maioria dos alunos e como consequência, a aversão a esta disciplina. $O$ ensino ainda realizado por meio de giz e uso do quadro negro deixam as aulas cansativas, contribuindo ainda mais, no desinteresse pela matemática, aulas se tornam cansativas, maçantes e muitas vezes sem aplicação cotidiana. Esse aspecto da abstração, por parte dos professores, excluindo a parte prática, potencializa tal aversão, pois este tipo de abordagem deixa o aluno muitas vezes fora da sua realidade de mundo. (SOUZA, 2018).

Fragoso (2001), apud Souza (2018) acrescenta que a abstração produz situações irreais por meio de cálculos grandes e complicados, descaracterizando situações reais de problemas em que os alunos poderiam apreciar suas vontades de resolvê-los, neste sentido, não há o favorecimento da necessidade de encontrar meios para se chegar a respostas no mundo em que vivem.

Ao aproximar o aluno de uma atividade interativa, poderá promover um contexto de ensino mais favorável, onde os conceitos que estão sendo ou serão apresentados possam dar contribuições para sua vivência de mundo. As noções de Estatística Descritiva inserem-se como conteúdos da matemática, sendo organizada pelas políticas públicas.

Segundo os Parâmetros Curriculares Nacionais - PCN's (1998) a estatística no ensino fundamental I e II é apresentada como tratamento da informação dividida em 4 blocos compreendidos entre os anos iniciais e finais do $1^{\circ}$ ao $9^{\circ}$ ano, respectivamente. Assim, os Parâmetros Curriculares Nacionais explicitam que o estudo estatístico tem como caráter, o tratamento da informação, possibilitando aos alunos neste nível de escolarização, compreender a realidade que o cerca, estabelecendo relações e justificativas no desenvolvimento do pensamento investigativo.

Muito além da leitura e interpretação de gráficos é tornar os alunos capazes de descrever e entender a sua própria vivência por meio dos conhecimentos matemáticos.

Os alunos poderão fazer conjecturas e representações, possibilitando o desenvolvimento entre a linguagem matemática e materna, ou seja, a matemática que tem ação direta na sociedade proporcionando a capacidade de comprar, vender, somar, estimar quantidades, caracterizando pensamentos matemáticos na resolução de situações cotidianas como uma linguagem de comunicação.

É importante ressaltar que o processo de avanço nos aspectos de aprendizagem e cognição da criança nestes ciclos, ainda assim, as generalizações feitas são simples justamente devido à própria capacidade de observação e experimentação das representações das informações, sem chegar a um processo de sistematização conceitual.

Para o ensino médio, a estatística descritiva tem papel de oferecer subsídios para o desenvolvimento de estudos, por exemplo, de conjuntos finitos de dados podendo ser este conjunto numérico, ou seja, com aspectos quantitativos, ou de caráter qualitativos de acordo com as informações que foram coletadas, o que caracteriza métodos da análise combinatória e medidas de tendência central e dispersão. ( $P C N+, 2000)$. 
Estamos num momento de reflexão de revisão do Ensino Médio e discussões que estão em andamento uma base nacional curricular comum (BNCC), recentemente promulgada. Esta versão preliminar corrobora para o ensino da estatística e da probabilidade, desde os anos iniciais do Ensino Fundamental, justificando que em diversos currículos fora do Brasil, além de ser evidenciado em pesquisas, que este tema é fundamental na Educação Básica (BNCC, 2017).

Neste caso, o uso do computador e das tecnologias da informação e comunicação (TICs) em particular no ensino da matemática, o "software GeoGebra" assim como outros recursos da tecnologia podem tornar o conteúdo da estatística mais atraente e significativo para o aluno, permitindo que façam uma análise envolvendo aspectos qualitativos e quantitativos diante do que estão observando (ARAUJO; ABID, 2003).

O presente artigo traz parte de uma pesquisa que está sendo realizada no Mestrado Profissionalizante no Ensino de Ciências e Matemática em que analisamos por meio dos resultados, a eficiência de uma sequência didática elaborada e aplicada que incluiu o GeoGebra, para o ensino e aprendizagem dos conceitos da estatística descritiva nos alunos do terceiro ano do ensino médio.

Pretende-se contemplar a necessidade da adequação do "software GeoGebra" para promover o desenvolvimento dos conhecimentos nos alunos, com diferentes motivações e interesses, criando condições para a sua inserção num mundo em mudança e contribuindo para desenvolver capacidades que deles serão exigidas em sua vida social e profissional.

No desenvolvimento de uma atividade dinâmica que neste caso, se faz por meio do dos recursos das tecnologias da informação e comunicação (TIC) com uso do computador em particular no ensino da matemática, o "software GeoGebra" assim como outros recursos podem tornar o conteúdo da estatística mais atraente e desafiador, permitindo que façam análises envolvendo aspectos qualitativos e quantitativos diante do que estão observando. (ARAUJO; ABID, 2003).

Portanto, o uso do "software GeoGebra" busca a interatividade auxiliando professor-aluno no processo de ensino - aprendizagem, procurando novas formas de solucionar as atividades propostas em sala de aula. Este software é gratuito, dinâmico e escrito em uma programação em Java, o que permite sua execução em multiplataforma (Microsoft Windows, Linux, Macintosh, etc.) podendo ser utilizado em todos os níveis de ensino, onde combina a geometria, álgebra, elaboração de tabelas, formação de gráficos, e cálculos estatísticos em uma única aplicação, um software livre, que vai de encontro de novas estratégias de ensino e aprendizagem, permitindo explorar, conjecturar, investigar tais conteúdos na construção do conhecimento matemático.

A pesquisa mencionada caracterizou-se num primeiro momento, em uma revisão da literatura de diferentes autores de referência, na área da tecnologia da informação e comunicação aplicada a educação matemática e da teoria da aprendizagem significativa, bem como, num estudo de caso, realizado com uma turma do terceiro ano do ensino médio. 
Como método de pesquisa o estudo de caso é usado em muitas situações, para contribuir ao nosso conhecimento dos fenômenos individuais, grupais, organizacionais, sociais, políticos e relacionados. Naturalmente o estudo de caso é um método de pesquisa comum na psicologia, sociologia, ciência política, antropologia, assistência social, administração, educação, enfermagem e planejamento comunitário. (YIN, 2015, p. 4).

É um método de pesquisa que compreende a dinâmica apresentada dentro de contextos específicos, além de descrever um fenômeno, o estudo de Caso tem caráter de profundidade e detalhamento.

A sequência didática descrita neste artigo considera a concepção de Zabala (1998). Segundo Zabala, uma sequência didática caracteriza-se em etapas contínuas de atividades, quando se faz o delineamento de um tema com o objetivo de ensinar conteúdos encadeados em etapas (ZABALA, 1998, p. 18, apud Machado, 2016). Araújo (2013) acrescenta dizendo que a sequência didática é a organização sistemática da prática de ensino, ocorrendo por meio da descrição e detalhamento dos conteúdos que os alunos precisarão realizar.

Portanto, a sequência didática, tem como finalidade a organização para o desenvolvimento de um conjunto de atividades educacionais, a fim de atender as necessidades do aluno.

A sequência didática que se refere este recorte, incluiu uma ferramenta tecnológica, o GeoGebra, como componente de um ambiente dinâmico de ensino em um contexto organizado e por meio de avaliações 1 e 2 ofereceram dados para inferir a eficiência desta sequência que se constituiu no problema investigado.

A pesquisa contou com a participação de 8 alunos ao longo do mês de novembro a dezembro/2018. No total, foram realizados oito encontros, sendo um por semana, com duração de 50 minutos cada, sempre após o período regular de aulas.

Após a coleta de dados que se deu por meio da avaliação 1, composta por duas atividades $1 \mathrm{~A}$ e $1 \mathrm{~B}$ com a finalidade de verificar quais os conhecimentos iniciais sobre a estatística descritiva e feita uma análise desses resultados, e no encontro 2, teve o início da aplicação da sequência didática que incluía o software GeoGebra, envolvendo os mesmos conceitos estatísticos.

Encontro 2: Conceitos básicos

A realização do encontro ocorreu distribuindo-se para todos os participantes da pesquisa, um texto informativo sobre estatística como o tema de uma loja do ramo de turismo, que apresenta uma pesquisa de satisfação sobre os valores dos serviços prestados, o número de acompanhantes e de passeios e a qualidade dos serviços prestados em relação às viagens oferecidas.

O objetivo deste encontro foi a retomada de conceitos como: população e amostra, com o propósito de identificar as variáveis qualitativas e quantitativas discretas e contínuas e através do texto elencado cima, Fizeram uma análise sobre as informações na identificação de elementos que eles julgaram ser da estatística descritiva.

Encontro 3: Elaboração da planilha de dados no GeoGebra. 
Este encontro teve como objetivo, a apresentação do "software GeoGebra", em uma sala multimídia e a elaboração da planilha de cálculo, com a finalidade de adaptação e conhecimento dos participantes com a plataforma. Inicialmente, foi apresentada a tela inicial com a barra de ferramentas e em seguida, uma segunda tela mostrando as regiões que foram trabalhadas.

Ao final da apresentação foi sugerida uma coleta das médias bimestrais da sala, referente ao $2^{\circ}$ bimestre do ano letivo de 2018 da disciplina de matemática, e que as mesmas, fossem registradas em uma folha de caderno para serem utilizadas no próximo encontro.

Encontro 4: Construção de tabela com a distribuição de frequência absoluta, relativa, medidas de tendência central e medidas de dispersão no GeoGebra.

O objetivo deste encontro foi a inserção dos dados coletados no encontro 2, na planilha de cálculo elaborada no GeoGebra, além da criação da tabela de frequências absolutas e relativas, possibilitando as medidas de tendência central e dispersão. Os conceitos da estatística descritiva foram apresentados oralmente seguindo a sequência didática, em que cada aluno tinha individualmente.

A seguir, mostraremos as etapas da sequência didática sendo realizada tanto em sala aula e no laboratório de informática da própria instituição escolar. Cada aluno ficou em um computador, sendo que todos já estavam com o programa GeoGebra instalado previamente e todas as atividades desenvolvidas foram salvas no programa. Posteriormente, foi possível fazer a análise dos registros realizados nessas pastas permitindo chegar aos resultados da pesquisa. Foi utilizado para análise das respostas dos alunos o seguinte critério: os oito alunos foram nomeados com as letras: A, D, G, L, $\mathrm{M}, \mathrm{P}, \mathrm{T}, \mathrm{V}$.

Os procedimentos aconteceram em cinco momentos distintos que se deram em avaliação 1 - sequência didática - avaliação 2 , sendo que a sequência didática foi realizada em três encontros e com os devidos cuidados na elaboração das avaliações 1 e 2 com conteúdos similares da estatística descritiva, de modo a alcançar os objetivos da pesquisa em questão.

\section{Detalhando o recorte e os dados parciais}

\section{Avaliação 1:}

Formada por um conjunto de atividades teve como objetivo avaliar o grau de conhecimento dos alunos sobre o conteúdo de estatística ensinado ocorrendo no pósperíodo regular de aula, com duração de cinquenta minutos. O desenvolvimento se deu por meio da distribuição de um texto aos participantes, relatando uma pesquisa sobre uma loja de serviços veterinários e após a análise, identificarem elementos que julgarem ser de conhecimentos estatísticos. Após essa leitura, responderam a um questionário no próprio texto, visando o reconhecimento sobre população, amostra e variáveis.

Por questão de espaço e limitação para este artigo, segue o recorte da avaliação 1 realizada pela aluna $A$ : 
Quadro 3 - Respostas incorretas da avaliação 1 parte B Fonte: arquivo do próprio autor

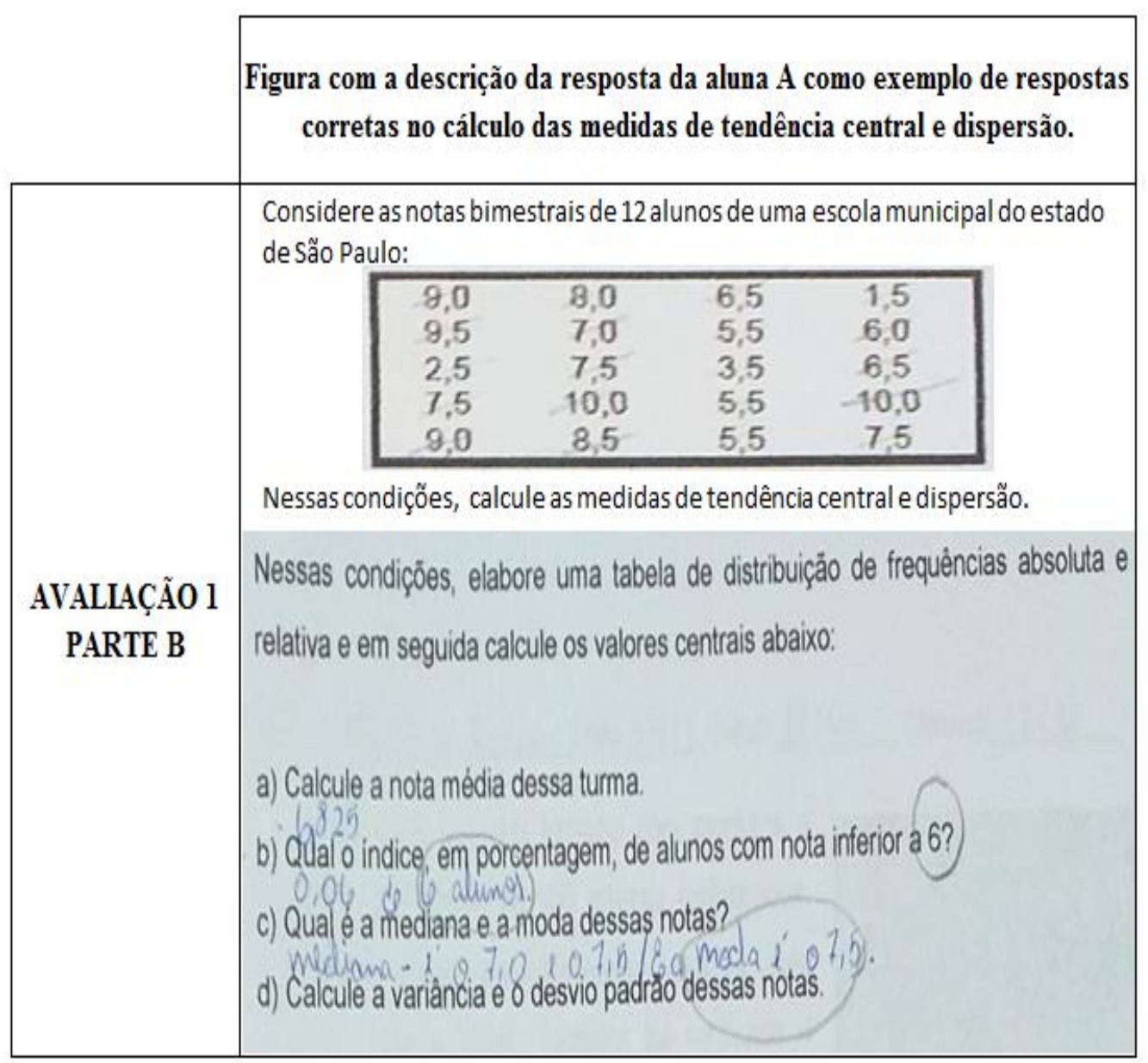

Dos resultados analisados na parte $A$, verificamos que os alunos confundem conceitos de variáveis qualitativa e quantitativa o que não permite classificá-las em discretas ou contínuas. Já na parte B, apresentaram dificuldades na organização da tabela de frequências absoluta e relativa, que permite o cálculo da média e dos demais indicadores da estatística descritiva além de revelar pouco trabalho mental organizado.

Encontro 2: A realização do segundo encontro ocorreu após o período regular de aulas com cinquenta minutos de duração. Foi proposta uma atividade objetivando uma revisão dos conceitos da estatística descritiva sobre população, amostra e variáveis qualitativas e quantitativas, esta última em discreta e contínua.

Encontro 3: O terceiro encontro foi direcionado para a apresentação da interface do GeoGebra sendo que nenhum aluno havia apresentado anteriormente, qualquer tipo de contato com programa, conforme figura 3. 
Ir até a barra de ferramentas na parte superior e clique no icone Exibir e imediatamente após, clique em planilha, e na tela de visualização ao lado direito, aparecerá a planilha

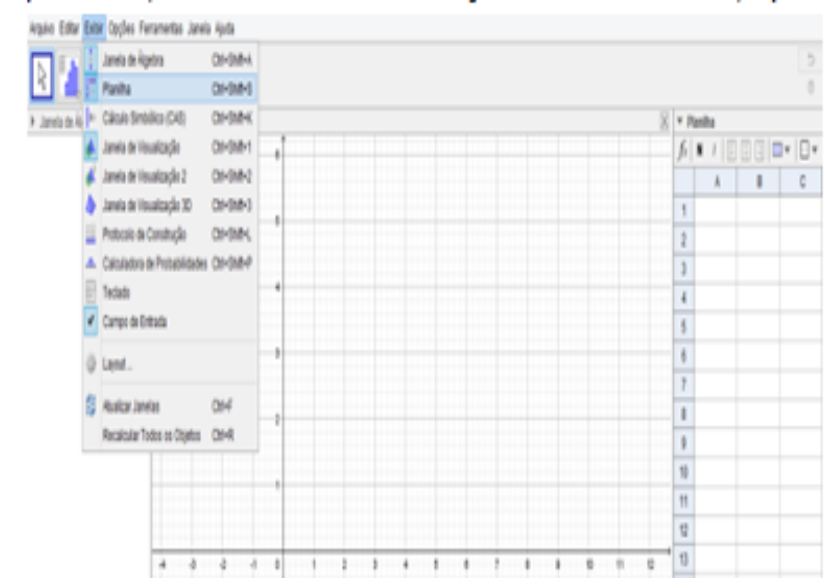

Figura 3: Fonte: GeoGebra 2015 - Planilha de dados

Ao final, julgamos que os participantes sejam capazes de reconhecer e manusear o "software GeoGebra", bem como realizar construções das planilhas de cálculo.

Encontro 4: O quarto encontro, o mais longo, foi subdividido em etapas ilustrando a construção de cada objetivo solicitado. $\mathrm{Na}$ etapa 1 é apresentada a elaboração da planilha de cálculos para a inserção de dados, veja figura 4:

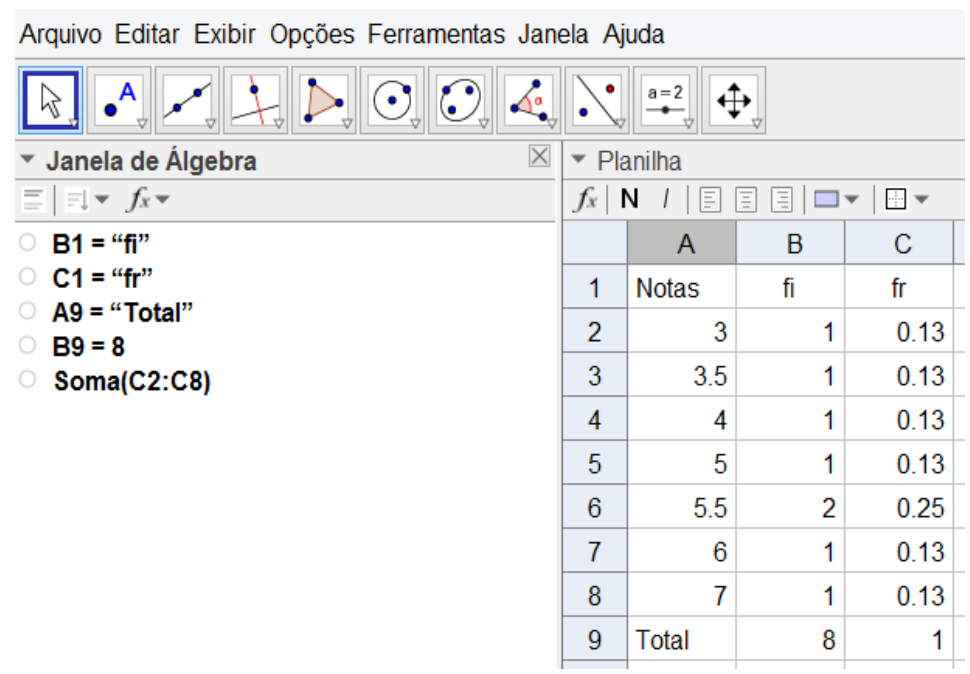

Figura 4: Fonte das atividades dos alunos desenvolvida no GeoGebra por meio da sequência didática para elaboração da planilha de cálculos com a variável, frequência absoluta e relativa.

Nesse momento, cada aluno estava em um computador e com a sequência didática impressa, foram realizando a atividade alimentando a planilha de cálculos no programa, vale ressaltar que nenhum aluno apresentou grandes dificuldades para executar tal tarefa, pois já haviam criados a mesma planilha no encontro 3.

$\mathrm{Na}$ etapa 2, houve a construção da tabela de frequência absoluta e relativa seguindo a sequência didática e através da planilha preenchida, clicaram com o botão direito do mouse sobre a célula A1 e pressionando a tecla shift selecionaram os dados por 
meio das setas direcionais, em seguida, deram um clique com o botão direito do mouse sobre a planilha já selecionada e criaram a tabela, ver figura 5.

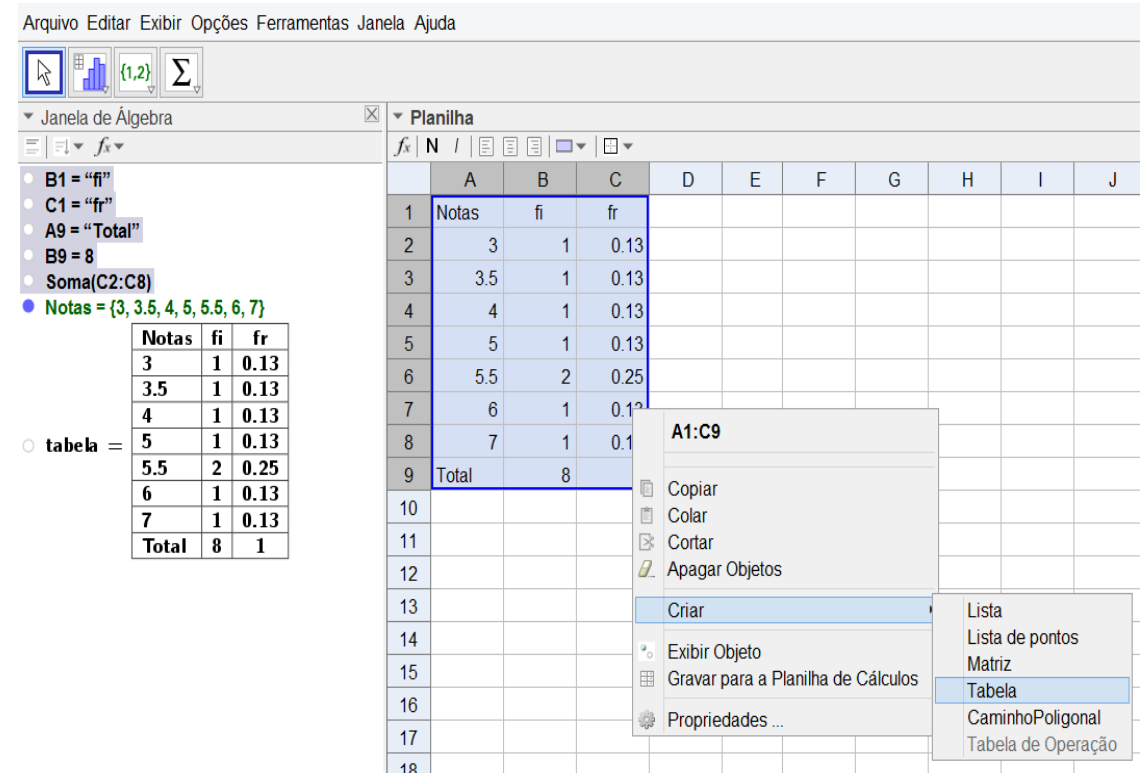

Figura 5: Construção da tabela de frequência absoluta e relativa.

É possível observar a tabela de frequências absoluta e relativa que os alunos construíram na janela de álgebra. Todos executaram a construção juntamente com a sequência didática.

Para a elaboração, da etapa 3, seguiram a sequência selecionando a planilha em seguida com o botão direito do mouse criaram uma lista de dados da variável notas bimestrais, conforme apresentado na figura 6 :

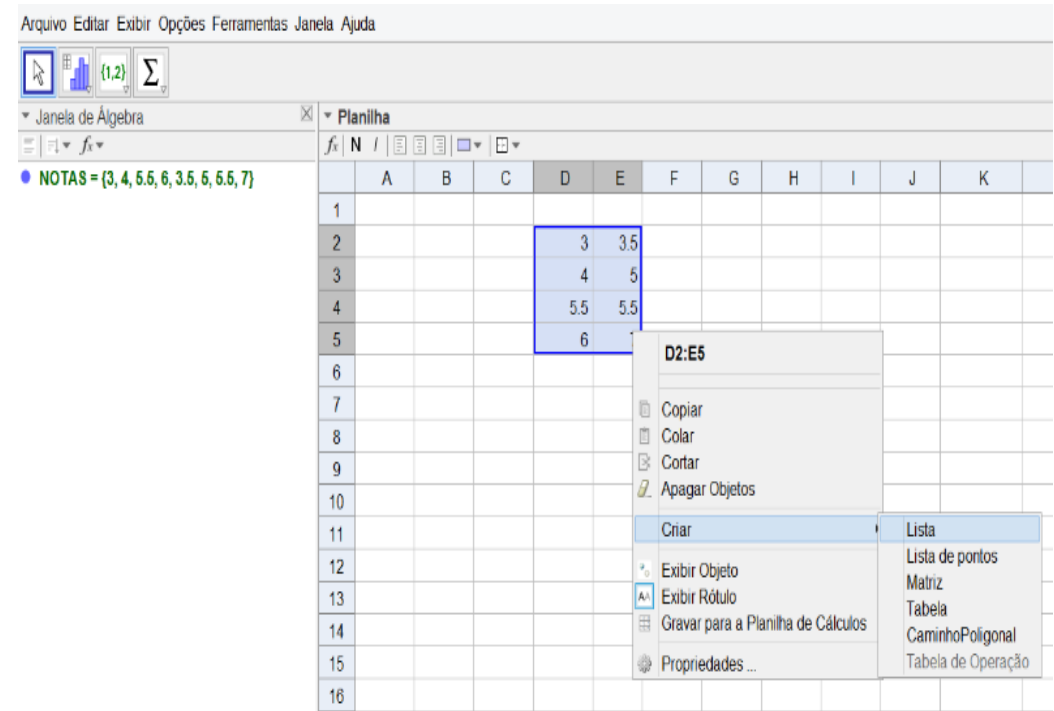

Figura 6: Fonte: GeoGebra 2015 - Visualização da lista de dados.

Posteriormente a essa construção, foi possível realizar os indicadores média simples, moda, mediana e as medidas de dispersão digitando na caixa de entrada a medida a ser calculada, conforme figura 7 e 8 : 


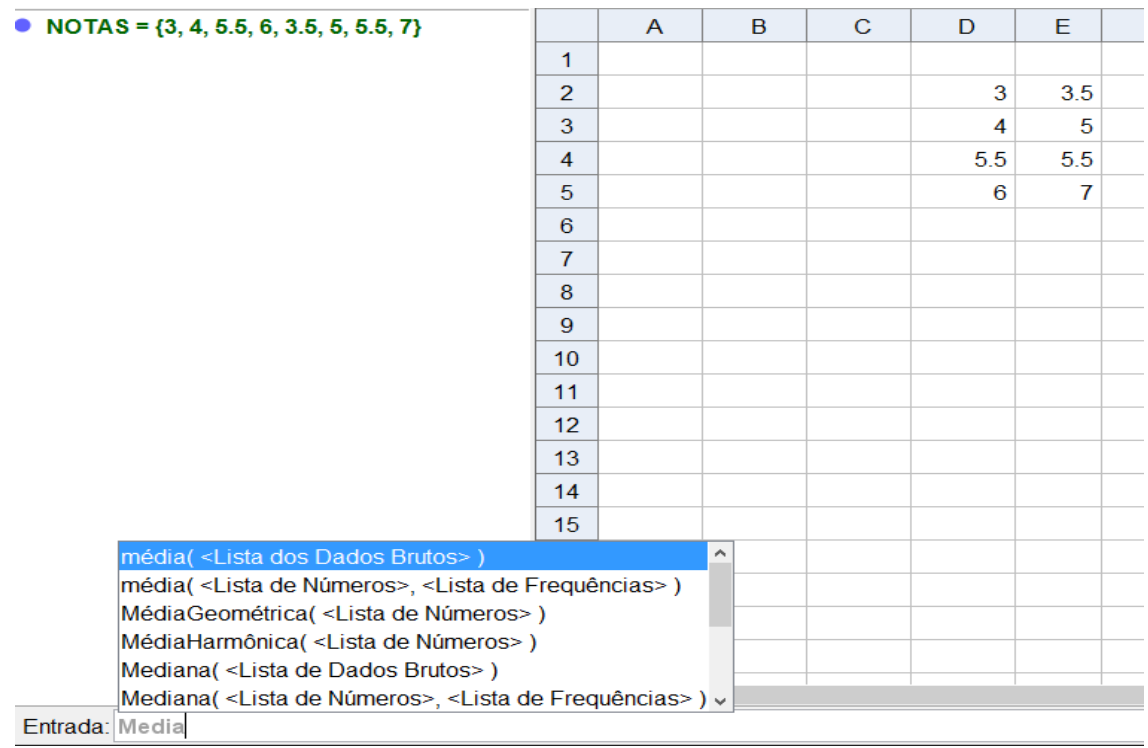

Figura 7: Fonte: GeoGebra 2015 - Comando na caixa de entrada.

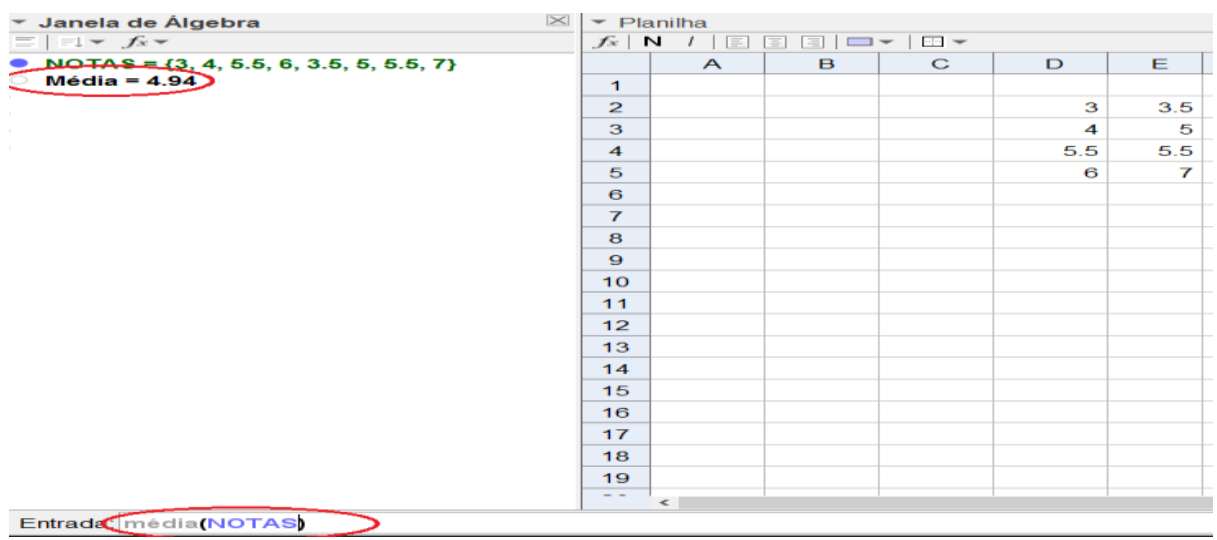

Figura 8: Fonte: GeoGebra 2015 - medidas de tendência central: média simples obtida após digitar "NOTAS" no comando na caixa de entrada

Para os demais indicadores estatísticos, mediana, moda e desvio padrão, seguem o mesmo procedimento, observe a figura 9:

Arquivo Editar Exibir Opções Ferramentas Janela Ajuda

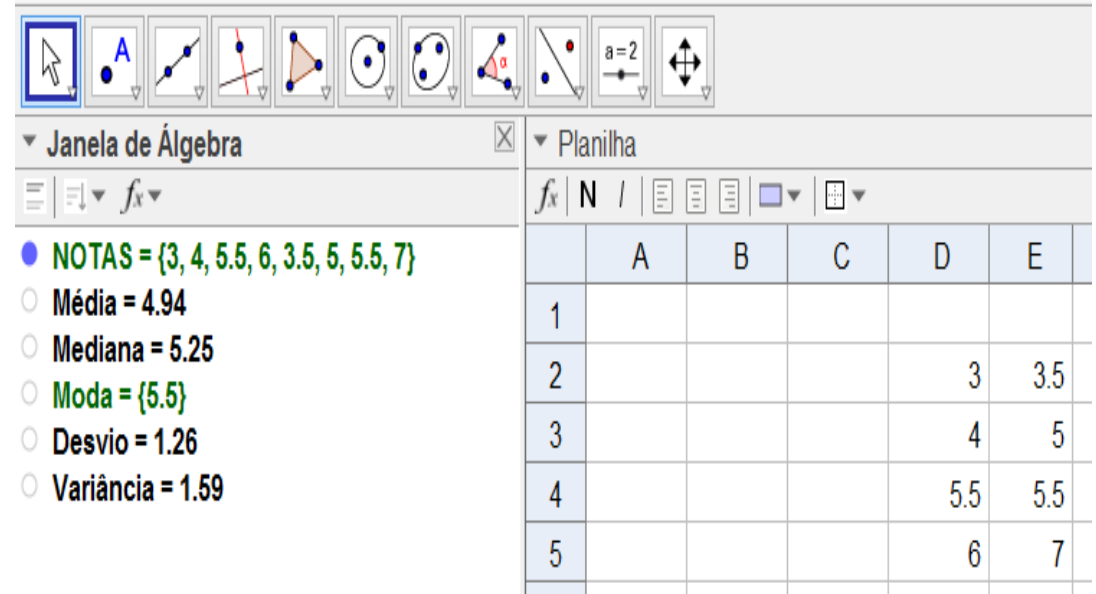


Figura 9: medidas de tendência central: mdia simples, mediana, moda e desvio padrão na janela de álgebra.

Ao final da sequência os alunos puderam gravar todo o trabalho realizado no GeoGebra em sua área de trabalho ou em um pen-drive. Para salvar, basta clicar com o botão esquerdo do mouse em arquivo e após clicar em gravar, conforme figura 10.

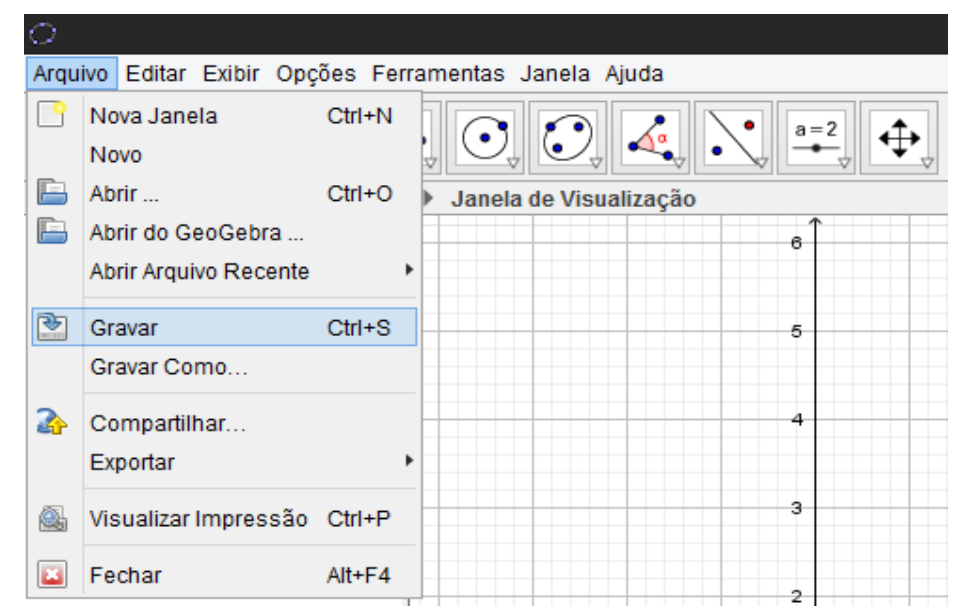

Figura 10: Fonte: GeoGebra 2015 - Gravação da atividade realizada no GeoGebra.

Encontro 5: Neste encontro, se deu a realização da avaliação 2, composta por duas atividades $2 \mathrm{~A}$ e $2 \mathrm{~B}$, uma semana após a aplicação da sequência didática, com o objetivo de avaliar o grau de conhecimento dos alunos decorrente da aplicação da sequência didática.

Por questão de espaço e limitação o recorte da avaliação 2 é da referida aluna $A$, que realizou a avaliação 1 .

Quadro 4 - Respostas corretas da avaliação 2 parte A

Fonte: arquivo do próprio autor

\begin{tabular}{|c|c|}
\hline & $\begin{array}{l}\text { Figura com a descrição da resposta da aluna A como exemplo de respostas } \\
\text { corretas dos conceitos sobre população, amostra e os tipos de varíáveis. }\end{array}$ \\
\hline $\begin{array}{c}\text { AVALIAÇÃO02 } \\
\text { PARTE A }\end{array}$ & 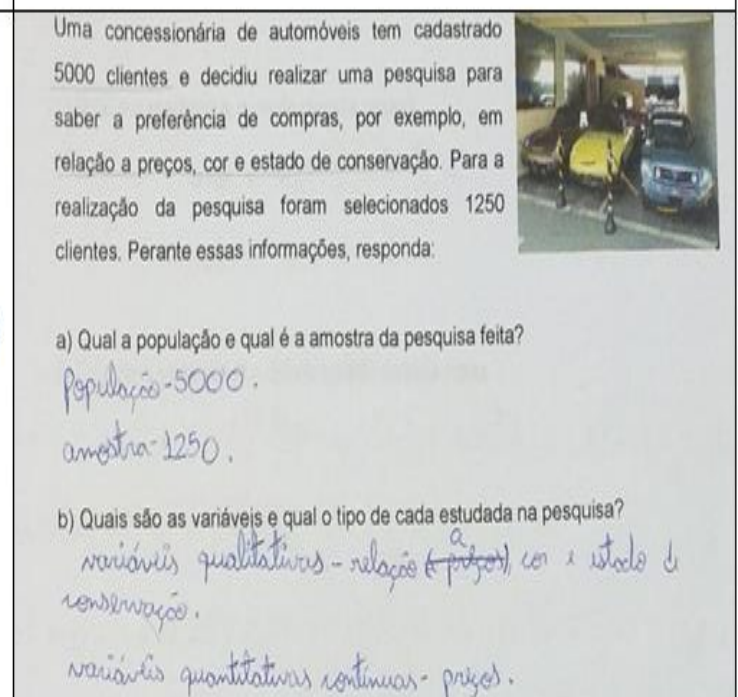 \\
\hline
\end{tabular}


Quadro 5 - Respostas corretas da avaliação 2 parte B Fonte: arquivo do próprio autor

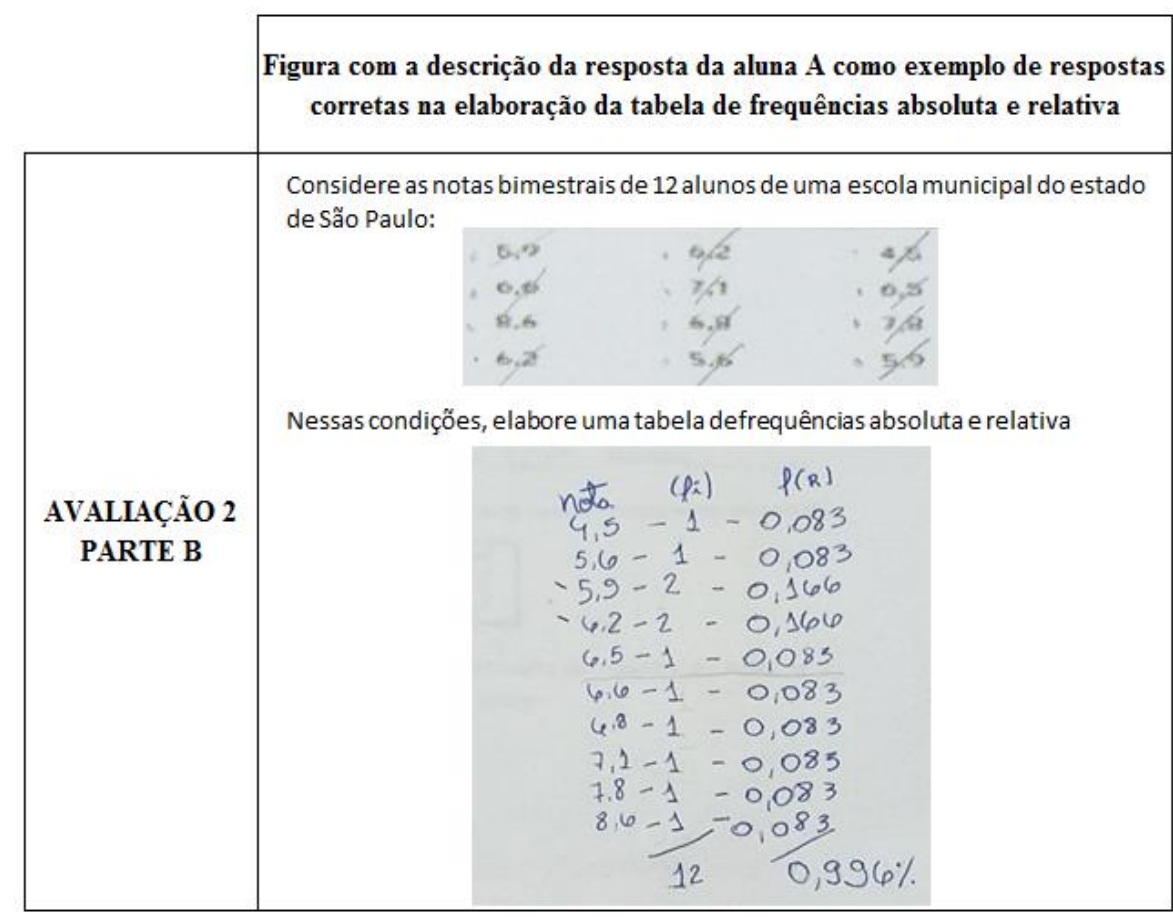

\section{Quadro 6 - Respostas corretas da avaliação 2 parte B Fonte: arquivo do próprio autor}

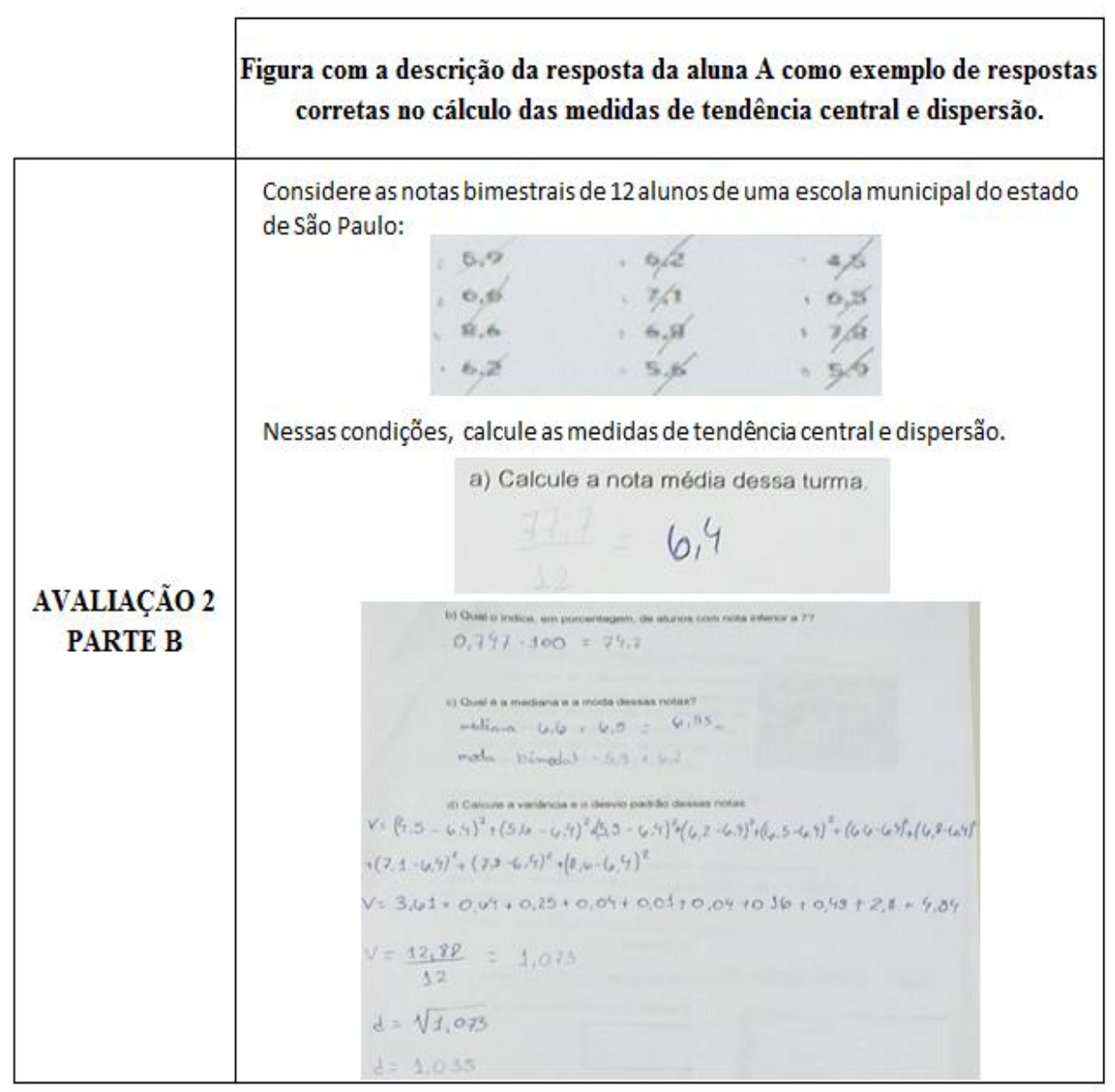


Uma semana a pós a aplicação da sequência, esperávamos que os participantes fossem capazes de reconhecer os tipos de variáveis e identificar a população e a amostra. O desenvolvimento se deu por meio da distribuição de um texto aos participantes, relatando uma pesquisa sobre uma concessionária de automóveis, e após a análise, identificarem elementos que julgarem ser de conhecimentos estatísticos. Após essa leitura, responderam a um questionário no próprio texto, visando o reconhecimento sobre população, amostra e variáveis.

A análise das respostas fornecidas indica que, apenas um dos oito alunos não apresentou conceitos claros em relação às variáveis qualitativas e quantitativas, já para os demais conceitos população e amostra, todos responderam corretamente.

Durante a análise, pudemos perceber que os objetivos não foram alcançados totalmente, quando se constatou que apenas dois dos oito alunos assimilaram os conceitos de medidas de dispersão, os restantes ainda continuam apresentando dificuldades no desenvolvimento do cálculo. Por outro lado, foi possível obter êxito na construção da tabela de frequência absoluta e relativa, o que permite com mais facilidade a organização dos dados e calcular os demais indicadores de medidas de tendencial central, além da concentração e da participação de todos durante a realização das atividades.

\section{Considerações finais}

Para ilustrar parcialmente o trabalho da dissertação no programa de mestrado e com o objetivo de verificar se a sequência didática incluindo o GeoGebra se houve contribuição para ensinar os conceitos da estatística descritiva envolvendo os alunos do terceiro ano do ensino médio, analisamos os resultados da avaliação 1, composta por duas atividades $1 \mathrm{~A}$ e $1 \mathrm{~B}$ e constatamos que os alunos apresentavam poucos conceitos sobre os tipos de variáveis, construção da tabela de frequências absoluta e relativa e na execução dos cálculos das medidas de tendência central e dispersão, neste último, conforme a análise, nenhum dos alunos tinham conceitos claros, o que não permitiu, determinar esse indicador.

$\mathrm{Na}$ dissertação é indicado como as avaliações 1 e 2 ofereceram dados para inferir a eficiência da sequência didática, que se constitui no problema investigado.

$\mathrm{Na}$ avaliação 2 composta por duas atividades $2^{\mathrm{a}}$ e $2 \mathrm{~B}$ e realizada após a sequência didática, os resultados apresentaram-se satisfatórios, ainda que esses resultados apontaram dois, dos oito alunos que passaram a apresentar conceitos para medidas de dispersão, por outra lado, mostraram que houve uma contribuição para potencializar os demais conceitos da estatística descritiva.

Em relação ao recurso da tecnologia utilizado na sequência didática, em particular, o uso do Geogebra, verificamos que o trabalho realizado com o computador, pode facilitar o processo de ensino - aprendizagem da estatística, à frente de uma visualização das possíveis variações alterando-se elementos da planilha de dados, podendo ser verificado esses efeitos tanto na tabela de frequência absoluta e relativa, como nas medidas de tendência central e dispersão, tais variações não são permitidas apenas em salas de aula. 
Os variados tipos de softwares, promove o desenvolvimento de conceitos básicos da estatística descritiva, além de um ambiente interativo. Nessa mesma linha de pensamentos, vem os Parâmetros Curriculares Nacionais para o ensino médio - PCNEM afirmando que o uso das calculadoras e dos computadores neste contexto, ganham destaques como recursos que promovem além da aproximação dos alunos com a tecnologia e familiarização com os diversos softwares, uma nova abordagem na resolução de problemas.

O GeoGebra, passou a ser uma ferramenta auxiliadora na realização de tarefas revolucionando e mudando o ensino onde, somente prevalecia lousa, giz, e poucos recursos que eram até então, os livros didáticos.

\section{REFERÊNCIAS}

ARAUJO, D. L. O que é (e como faz sequência didática)? Rev. Entrepalavras, v.3, n.1, p. $322-334$, jan/jul, 2013.

ARAUJO, M. S. T.; ABIBI, M. L. V. S. Diferentes enfoques, diferentes finalidades. Rev. Brasileira de Ensino de Física, v. 25, n.2, Jun. 2003

ARAUJO, D. L. O que é (e como faz sequência didática)? Rev. Entrepalavras, v.3, n.1, p. 322 - 334, jan/jul, 2013.

BARRETO R.G. Discursos, tecnologia, educação. Rio de Janeiro. EdUERJ, 2009 BRASIL. Secretaria de Educação Fundamental. Parâmetros Curriculares Nacionais. Brasília: MEC/SEF, 1997.

BRASIL. Secretaria de Educação Fundamental. Parâmetros Curriculares Nacionais. Brasília: MEC/SEF, 1998.

BRASIL. Ministério da Educação. Parâmetros Curriculares Nacionais Ensino Médio. Brasília: MEC.

Disponível em: <https://www.geogebra.org/download?lang=ptAcesso em: 21/abr> Acesso em: 25/jun. 2018

FERRI, J. SHIMIGUEL, J. CALEJON, L. M. C. Uso do GeoGebra no ensino de Matemática. Rev. Gestão Universitária. 2013.

FERRI, J. C. O USO DO GEOGEBRA NO PROCESSO DE ESNINO APRENDIZAGEM DA MATEMÁTICA. 2015. - 111 f. Dissertação (Mestrado em Ensino de Ciências e Matemática) Universidade Cruzeiro do Sul, São Paulo, 2015.

FRAGOSO, W. C. O medo da matemática. Revista Educação. n. 02, v. 26, 2001.

LEIVAS, J. C. P. GOBBI, J. A. O software e a Engenharia Didática no Estudo de áreas e perímetros de figuras planas. Rev. Brasileira de Ensino de C\&T, v. 07, n. 01, 2014.

Ministério da Educação. Base Nacional Comum Curricular Proposta Preliminar. Brasília, 2017. Disponível em: Acesso em: 01de junho de 2018. 
MACHADO, J. T., A utilização do GeoGebra no ensino de cálculo de área no curso de Química: um relato da práxis docente. 2016. - 81 f. Dissertação (Mestrado em Ensino de Ciências e Matemática) - Universidade Cruzeiro do Sul, São Paulo, 2016.

SHIMIGUEL, J. et al. Contribuições das pesquisas de Doutorado em Tecnologia e Comunicação para o Ensino de Ciências e Matemática. In: ALLEVATO, N. S. G. CURI, E. (Orgs.). Ensino de Ciências e Matemática: o legado da pesquisa em 10 anos de doutorado Introdução. São Paulo: Paco Editorial, 2018. P. 119 -130.

SOUZA, R. F. O uso do Software GeoGebra no Ensino Aprendizagem da Estatística Descritiva: In: EBRAPEM - ENCONTRO BRSILEIRO DE ESTUDANTES DE PÓSGRADUAÇÃO EM EDUCAÇÃO MATEMÁTICA. XXII, Belo Horizonte. Anais, 2018. VERASZTO, E. V.; SILVA, D.; MIRANDA, N. A.; SIMON, F. O. Tecnologia: Buscando uma definição para o conceito. PRISMA.COM, n.7, 2008.

VERASZTO, E. V.; SILVA, D.; MIRANDA, N. A.; SIMON, F. O. Tecnologia: Buscando uma definição para o conceito. PRISMA.COM, n.8, 2009. 